\title{
SIEM: Santiago' (Chile) Integrated Energy Model
}

\author{
MIES: Modelo Integrado de Energía para Santiago, Chile
}

Alexandre Carbonnel Torralbo (Main and Corresponding Author)

Universidad de Santiago, Escuela de Arquitectura

Ave. Lib. Bernardo O’Higgins 3363. Estación Central. Santiago, Chile

alexandre.carbonnel@usach.cl

\section{Rodrigo Martin Quijada}

Universidad de Santiago, Escuela de Arquitectura

Ave. Lib. Bernardo O’Higgins 3363. Estación Central. Santiago, Chile

rodrigo.martin@usach.cl

Manuscript Code: 1014

Date of Acceptance/Reception: 30.11.2018/05.12.2017

DOI: 10.7764/RDLC.17.3.412

\begin{abstract}
This paper presents a framework for the "Santiago Integrated Energy Model" or SIEM. This model establishes an optimized energy balance between the photovoltaic generation potential and the electric consumption curves of a specific Urban Energy District (EUD), designed for the city of Santiago. To validate local data, a methodology has been developed in three stages: the potential prospection and the curves estimation; the data calibration; and the EUD identification. The model has been applied in an hypothetical urban area to develop a consistency test, obtaining adequate results on the balance curves of the model, considering both the potential generation and consumption (according to uses and schedules). The results reflect the relevance of applying this model to a real urban area in Santiago of Chile, to establish optimization correlations for an empirical validation.
\end{abstract}

Keys words: Energy balance model, photovoltaic potential, district energy, urban energy.

\section{Resumen}

Este artículo presenta un marco de desarrollo para el "Modelo integrado de energía para Santiago" o MIES. El modelo propone optimizar un balance energético entre el potencial de generación fotovoltaico y las curvas de consumo eléctricas de un determinado Distrito de Energía Urbano (DEU) para la ciudad de Santiago. Para validar datos locales, se desarrolla una metodología en tres etapas: la prospección del potencial de generación y la estimación de curvas de consumo eléctrico; la calibración de datos; y la identificación de un DEU. El modelo ha sido aplicado en un área hipotética urbana para desarrollar una prueba de concepto, obteniendo resultados adecuados sobre las curvas de balance del modelo, considerando tanto potencial de generación como consumo (según actividades y horarios). Los resultados sugieren la importancia de aplicar este modelo en un área urbana real en Santiago de Chile, para establecer una validación empírica mediante correlaciones de optimización.

Palabras clave: Modelo balance energético, potencial fotovoltaico, distrito energético, energía urbana.

\section{Introduction}

From an energy perspective, cities are like an urban grid with different morphological and spatial configurations and diverse land use types that generate different spatial-temporal patterns of energy consumption and demand. Accordingly, the Santiago Integrated Energy Model (SIEM) presented in this article aims to improve urban energy management on a district zone scale under an energy balance model, which takes into consideration energy generation and the efficient use of energy.

SIEM is a model for assessing both the energy generation potentials in the Santiago urban districts, and the energy consumption related to different activities present in the areas of the city. This model on its first stage, will be tested in an urban hypothetical area. The aim is to create, on a specific urban area, a balance between the generation potential and the dynamic consumption curves of a specific urban grid. These territorial units will be identified as Energy Urban Districts (EUD).

On urban areas, we can differentiate criteria as location, building size, density and land use among other, those that define different scale like neighborhood, building cluster, district, and municipalities (Voulis, Warnier, \& Brazier, 2018; Zhang et al., 2018). In Chile, the term district has been used for legal and political division of the territory, also as in informal term for financial concentrate areas. However in this paper EUD will be used to refer to an area nearly to neighborhood scale from an balance energy criteria. 
Currently, energy generation potential studies are focused on residential, institutional or commercial independent units (e.g., residential photovoltaic panels or wind generators). On the other hand, it is possible to understand the city as an inter-dependent territory and system, in which buildings create wind corridors or high solar exposure areas. Therefore, it is possible to transfer energy among units that operate based on different timeframes (households-businesses-offices, institutional buildings, schools and health institutions, among others), opening up new perspectives for the generation and management of clean and renewable energy generation within the cities.

Despite Energy plans are used in developed countries as a tool for energy management in the development of urban areas, such as the California Energy Action Plan in force since 2003, or the ten-year national energy plans of European countries in force until 2020, implementing them in many countries is still not mandatory. We firmly believe that the current urban management of the city consider energy for future sustainable and viable development. Reviewing both national and international advances in this area, allowed us to identify proposals and scenarios that point in this direction, i.e., efficient management and district redistribution of urban energy.

\section{Problem statement}

District energy and the improvement of urban energy management has emerged ultimately as a major theme (Yeo \& Lee, 2018; Zhang et al, 2018). The energy consumption of cities represents $66 \%$ of the planet global energy and generates more than $70 \%$ of global greenhouse gas emissions (Fragkias, Lobo, Strumsky \& Seto, 2013). In this scenario, energy management and distribution has become one of the most demanded and critical market goods, which has led to search for alternatives to the centralized power generation monopoly. This task comprises three essential aspects: increasing local and regional self-sufficiency (mainly Europe), opting for non-conventional renewable energies (NCRE) and confronting the gradual fall in global oil production.

In Chile, the generation of electricity management strategies has been focused on different scales: large supply companies connected to the central interconnected system (in Spanish, SIC), local generation plants mostly associated with productive areas, and finally the acquisition of photovoltaic panels by natural persons or companies for residential and business use. In the last scale, individual demand from buildings such as offices, dwellings and public premises, among others, presents an energy potential optimization that is essential to study.

Currently, the main studies and proposals at the country level have focused on individual demand based on generation potential; hence, the importance of improving this scenario trough a model that incorporates potential redistribution based on spatial-temporal consumption curves, is relevant to improve a local framework for EUD.

A study on a forestry zone in Viña del Mar, Chile, evaluated the energy potential of roofs in an area of 10 hectares within the conurbation of Valparaíso (Araya-Muñoz, Carvajal, Sáez-Carreño, Bensaid, \& Soto-Márquez, 2014). The study proposes a solar model that determines the energy potential for the area, which is based on the combination of $\mathrm{PCl}$ Geomatics / ArcSecene / ArcMap from epipolar images. The real use and geometrical configuration in a specific residential territory provides relevant information about generation potentials (solar radiation for 366 roofs during each hour of the year).

Even though the study does not consider demand based on energy consumption, it gives us significant references for the application of the SIEM in its calibration methodological stage. According to this study the estimate potential generation in the area of $5.86 \mathrm{kWh} / \mathrm{ha} /$ year.

Likewise, the municipality of Vitacura (Santiago, Chile) has provided an energy management tool based on Vitacura's solar map. Considering that $80.4 \%$ of the energy consumption of this municipality corresponds to residential areas, the municipal government, through an energy diagnosis and the definition of strategies and goals (Fundación Chile, 2014), has implemented an online platform to estimate the generation potential of all the roofs of the commune.

This tool has been designed to estimate the payback investment on a private photovoltaic system, focusing on the individual demand of residents and private owners. Therefore, does not represent a major change in terms of energy management and redistribution, an essential aspect that we attempt to highlight with the Energy Urban District (EUD) approach.

One study with a similar approach on residential houses (Zalamea \& Garcia, 2014) have developed a method to quantify photovoltaic and thermal energy production for single family houses in the city of Concepción, Chile. The results estimate that if the main or secondary roof sections of the house were covered with integrated photovoltaic system will be enough energy to supply the full average electricity needs of each home with possible surpluses for the urban grid. 
A second national study (Campos et al., 2018), related to the potential photovoltaic energy for city from more than 15.0000 inhabitants for the whole country, estimate that it is possible to cover a $22 \%$ of the total electricity demand of the country, based on the assessment for the city of Conception and extrapolating the results for the rest of the cities.

Despite the contributions of the national publications, to analyze the possibility to supply the entire demand of electric energy with renewable energy, the studies does not integrate electricity consumptions curves or different use typologies of buildings on a daily balance redistributions perspective like the SIEM proposes.

For consumption curves estimations, the main factors to consider are the activities carried out during the day and hours when buildings are used. Some international studies (Yao \& Steemers, 2005) have demonstrated relatively high correlations $(R=0.8425)$ between occupation predictive models and survey results. A study conducted in the UK established a model with patterns for the consumption curves of residential dwellings, which were divided into full-time working hours, part-time working hours and unemployed. These categories helped us to define the hours when households were occupied.

Nevertheless this model cannot be replicated in Chilean Districts, since families in the UK are different in composition, (one or two people occupy $66 \%$ of dwellings) and their work schedules are different from those of Chile, the study corroborated the relevance of modeling to estimate energy consumption curves when there were no consolidated national statistical data on the subject.

In spite of a study about the final use of energy in the residential sector have been conducted in Chile (CDT, 2010), data and information are centered on energy sources (electricity, wood, natural and liquefied gas, etc.) and domestic appliances that consume energy (heaters, air conditioning, refrigerator, etc.). This study describes relevant data, as we now know that $17.6 \%$ of energy consumed by dwellings is electrical, from which $67.4 \%$ corresponds to the fridge, lighting, television and appliance stand-by mode.

The study, however, does not provide disaggregated data on time schedules of energy use, and information about how household is distributed by thermal zone (Building Regulation O.G.U.C 4.1.10), which includes the estimation of energy thermal losses, but excludes variables related to spatial urban configuration, housing densities and occupation habits by socioeconomic class.

Another interesting study on the estimation of consumption curves is proposed by Gomez (2007), who points out a tendency of residential demand to concentrate at evening time, from 18:00 to 22:00. In this study, the demand of BT-1 clients from the grid is analyzed based on four clusters: residential (92\%), commercial (6.7\%), industrial and others (1.3\%). Results show consumption curves concentrated on the times specified. This could be considered as reference in the estimation of the consumption curves of the SIEM.

According to the above, we may conclude that although there is a tendency to incorporate more NCREs in energy generation, the models and analysis conducted have been oriented to the offering of private energy generation for dwellings or businesses. Those analysis models are restricted to generation potential, but without enhancing the diversified consumptions existing in the urban grid.

In the SIEM proposal we seek a change in this approach. Creating a management tool that allows finding a balance between the generation potentials and the consumption demand of an urban area, and thereby defining the unit or district (EUD) to be managed. The methodological framework for the application of the SIEM is exposed below.

\section{Methodology and model description}

SIEM is a proposal to integrate a balance approach between consumption profile activities and potential renewable energy generation on an urban area. Recent studies have been conducted on urban building energy modeling (Chen, Hong, \& Piette, 2017; Reinhart \& Davila, 2016), and several on the consumption profile estimation, like de occupancy presence model.

The consumption profile must be locally evaluated, since the local cultural habits, behaviors and the type of appliances differ from one country to the other. A method for predicting the energy load profile for houses in the UK (Yao \& Steemers, 2005), combines occupancy patterns and demand of electricity and heating, applying cluster analysis, and 
the result can be used as a reference. Although, the local characteristics must be measured to calibrate correctly the model.

To improve the energy simulations of buildings, the presence of users should be factored in the model, since user behavior can have a great impact in energy expenditure (Page, Robinson, Morel, \& Scartezzini, 2008). To simulate the activities of occupants, the use of Markov Chain based statistical methods has been used as an effective technique (Johnson, Starke, Abdelaziz, Jackson, \& Tolbert, 2014). Other stochastic models with a very precise time resolution (1 minute) have been used for the modelling of domestic activity patterns and the associated electricity demand, and the results show realistic patterns that can be used in energy simulations (Widen \& Wackelgard, 2010). Nonetheless, optimizing an urban area based on energy balance criteria is still a currently evolving subject.

In order to evaluate the application of mathematical models of generation and consumption assessment to delimitate an urban-spatial energy balance, we have developed a model (Figure 1) that includes a variety of activities located in a hypothetical urban area. This ensures varied consumption cycles, and the availability of three-dimensional information about the buildings, which allows the adequate assessment of the surfaces exposed to sunlight as well as solar radiation.

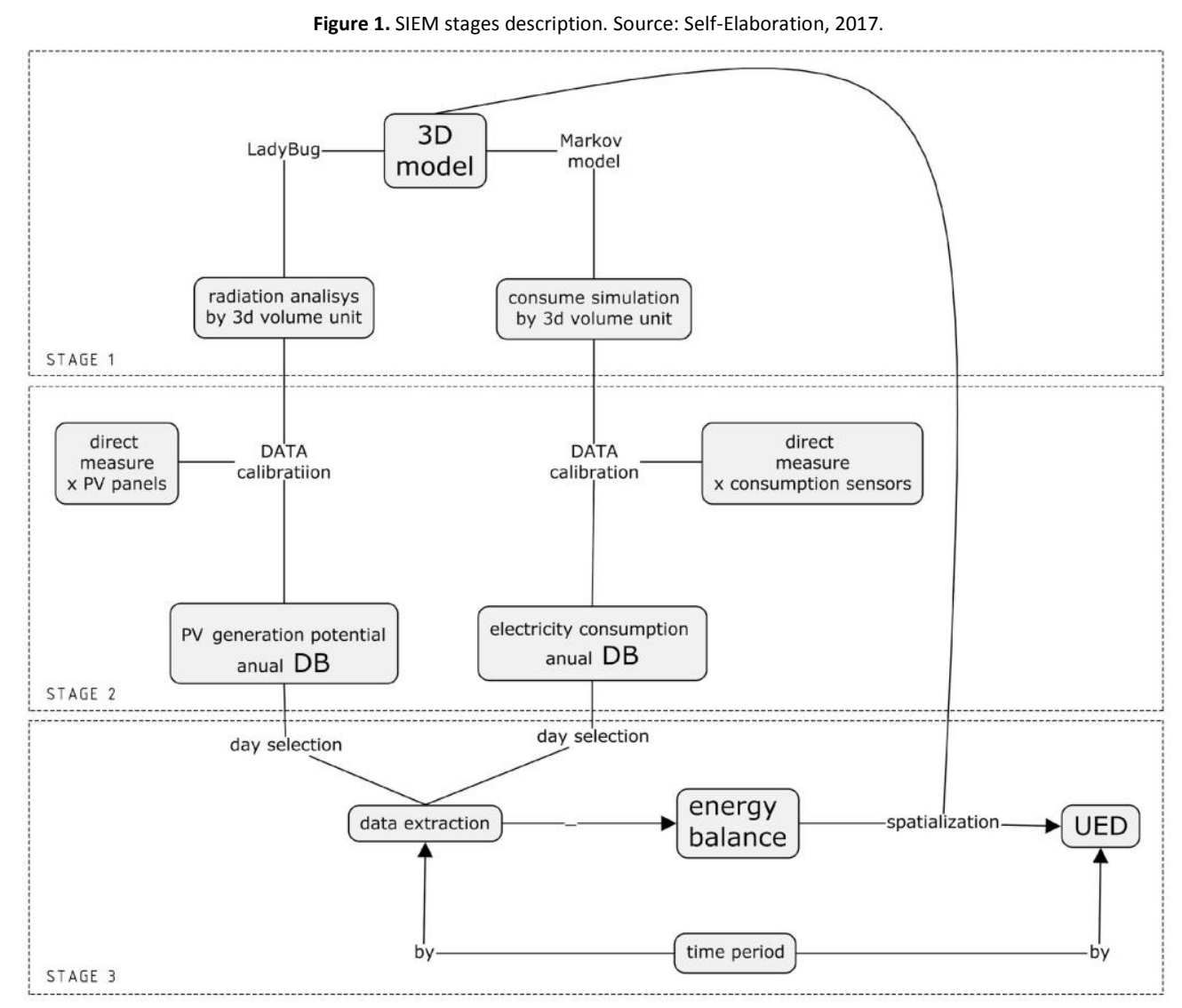

The consumption demand from activities carried out in the Santiago scenario and its temporal dynamics are directly related to the generation potential proposed by the SIEM. To define these types of consumption, activities need to be scheduled and the cycles and intensities of consumption need to be analyzed. To this end we propose using mathematical models and calibrating them through data collection.

The methodology is structured in three stages. The first stage sets the parameters to be applied to the integrated models for prospection of potential generation models and estimation of consumption curves.

The second stage is aimed at the empirical calibration of both models using field measurement. Finally, the third stage defines a conceptual approach to urban identification and management for the Energy Urban Districts (EUD). 


\section{Stage 1: Potential prospection and consumption curves estimation}

SIEM provides dynamic information about both generation and consumption potentials for an urban area, defining an Energy Urban District (UED). The integration of both generation and consumption information allows identification of urban areas in which an energy balance can be reached. Thus, two simultaneous approaches to the study have been proposed: Firstly, from the PV generation base, and secondly from the electricity consumption base. As a result, we define the balance-covered area as an UED.

The first approach consists of identifying the main urban generation surface space and quantifying their energy potential. To this end the surfaces of buildings exposed to sunlight are identified, and a database of irradiation in $\mathrm{KWh} / \mathrm{m}^{2}$ for every day of the year is made.

This analysis is conducted by estimating irradiation through the dynamic energy simulation software LadyBug(c). Here, EPW climate files from Meteonorm(c) corresponding to the area of Santiago are uploaded. An analysis of each surface exposed to the sun is reach in an hourly basis, measured in kWh. Finally, these data points are used to building a representation consisting of iso-value curves (Figure 2), where it is possible to observe the distribution of generation potentials located in the study area.

Figure 2. Analysis of USACH campus sun exposure. Source: Self-Elaboration, 2016.

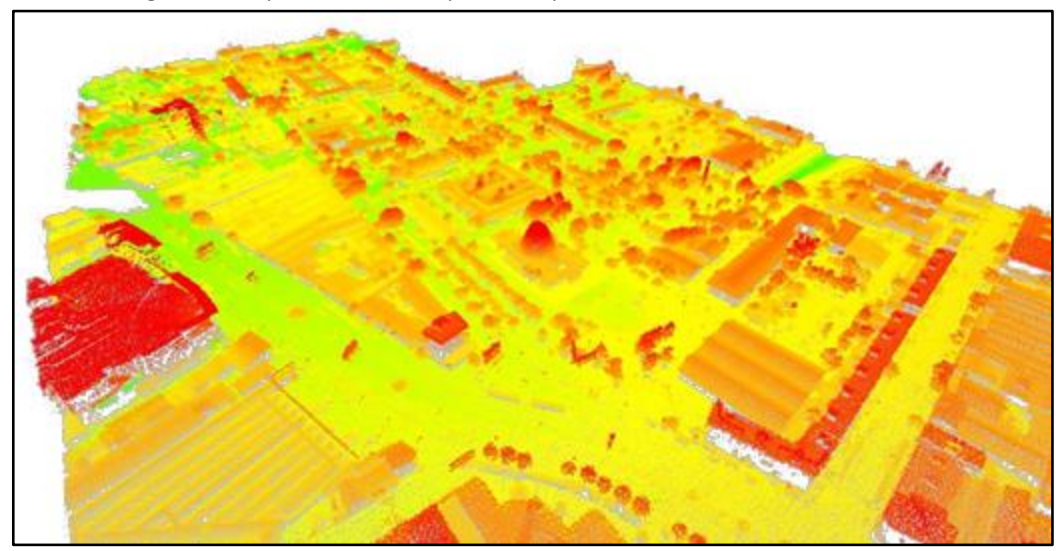

In conclusion to this first approach, and as a case study, the SIEM has estimated the potential of Universidad de Santiago de Chile (USACH)'s campus for PV solar generation based on a three-dimensional grid model (Figure 2). This campus has an area of $340.000 \mathrm{~m}^{2}$, and is located in the Estación Central commune in Santiago of Chile.

The second approach aims at obtaining a daily electricity consumption curve taking into account diverse urban activities. For this purpose, a Markov (probabilistic) model curve is assigned to each surface according to its use (households, commerce, offices or classrooms). This model (Figure 3) uses electricity consumption cycles estimations (households, commerce, offices or classrooms) based on data from international study cases (Wilke, Haldi, Scartezzini, \& Robinson, 2013). Thus, this model establishes the probability of occurrence of either of these consumption rates according to the time of the day, assigning a value to every unit (buildings or dwellings) at every hour of the day. The use of a stochastic model ensures a varied distribution of consumption for every activity identified. In this way the model approaches real behavior.

The model main objective is to combine the consumption curves of different energy consuming activities that take place in the area until achieving an hourly compensation of combined consumption. This consists in identifying a group of activities located in the area and combining their electricity consumption dynamics represented in daily curves in such a way that they are as close as possible to the photovoltaic generation curve. Since the generation curve is relatively constant and known, varying only across seasons (winter-summer), the adjustment of this curve is what we denominate "flattening", which corresponds to the differential between the generation curve and the combined consumption curves. 
Figure 3. Model for consumption assignation to households. Source: Self-elaboration, 2016.

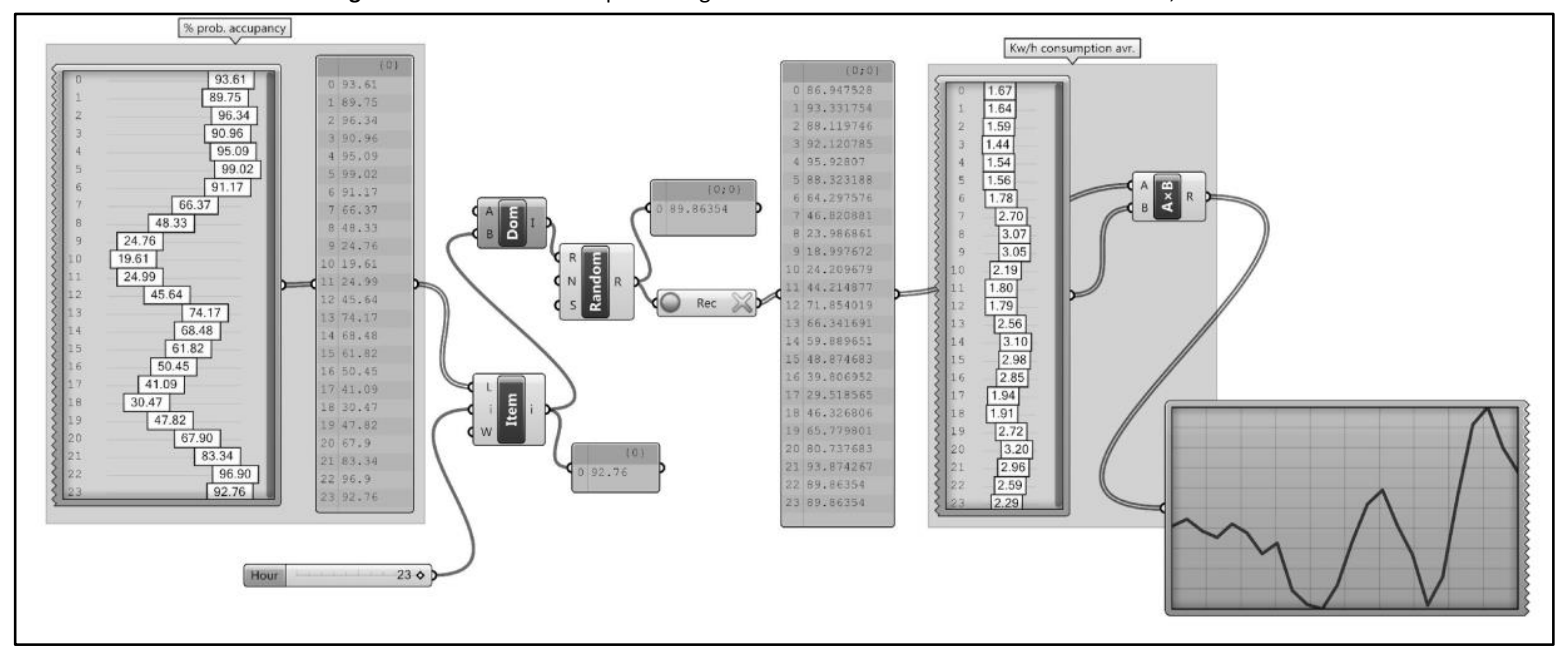

The consumption dynamics by activity behave in different ways; some of them are even complementary. For example, the consumption curve of a dwelling is hypothetical higher during the morning and evening, while the business curve behaves in the opposite way, i.e., its highest point occurs at noon. Consequently, when these two activities are added up, they present a consumption behavior more stable during the day. However, the net consumption of each activity should be considered, as the curve for commercial activities is generally higher than the one of households and therefore it should be evened with a larger quantity of dwellings. A second aspect to consider is the spatial distribution of these consumption units, because a compact unit that can be connected to the electricity grid is needed to achieve daily stability in terms of potential. Additionally, the energy demanded for maintaining this consumption rate covered during the day will be used to define the extension of the area necessary for energy balance and delimit the EUD surface.

As for the estimation models for consumption demand, studies that allow for the spatial-temporal estimation of energy demand have been conducted at the international level (Mikkola \& Lund, 2014). In general terms, these approaches estimate consumption patterns based on statistical data from energy use in buildings and population density.

In the Helsinki case analyzed in Mikkola \& Lund study, three consumption sectors were identified: residential with $59.3 \%$ (apartments, houses, and condominiums), services with 30.2\% (offices, health and education, recreational and commercial premises) and industrial (factories, storehouses) with 9.8\%. As expected, the results show higher consumption during daytime and weekdays for the service sector, while the residential sector concentrates consumption during the morning and afternoon, as well as weekends.

On a similar approach, a recent study (Voulis et al., 2018) of nearly 15.000 neighborhood on Netherland, which analyzes the demands profile and energy user compositions, determinated that it is possible to classify three cluster urban areas: residential, business and mixt based on the principal energy use in each area. Similar to the Mikkola and Lund results, the study confirm that the demand profile for residential type is concentrated on the evening hours, while for businesses type it present a plateau between 09:00 and 16:00, and finally, for the mixt type it shows a double peak between 09:00 to $20: 00 \mathrm{hrs}$.

These studies does validate the use of models for the spatial-temporal estimation of demand. Nevertheless, one of the problems inherent to this method is publicly data availability, since in cases like Santiago of Chile, for instance, there may be important deviations at identifying the real uses of the buildings as well as the times when they are used. Therefore, the model data needs to be calibrate empirically on a case study area in Santiago.

\section{Stage 2: Data calibration}

In this stage, the objective was to calibrate both potential and electrical consumption digital database. For this purpose, a set of six photovoltaic panels was installed on the roofs of the School of Architecture of Universidad de Santiago from July 2016 to July 2017. The empirical measurements of the generation potential of these panels provided enough data to remap the simulated values of PV potential in the digital prospection, for the precise location of the study case (Figure 4). 
To assess the electricity consumption curves of the city in an empirical way, six single-phase electricity consumption sensors were installed in locations with different urban activities (dwellings, businesses, offices and classrooms). The acquisition of the sensors, definition of study cases, development of an installation protocol, and the setting up of the sensors were carried out during 2016-2017. The empirical data was used to remap the simulated database of daily electricity consumption curves, to local values.

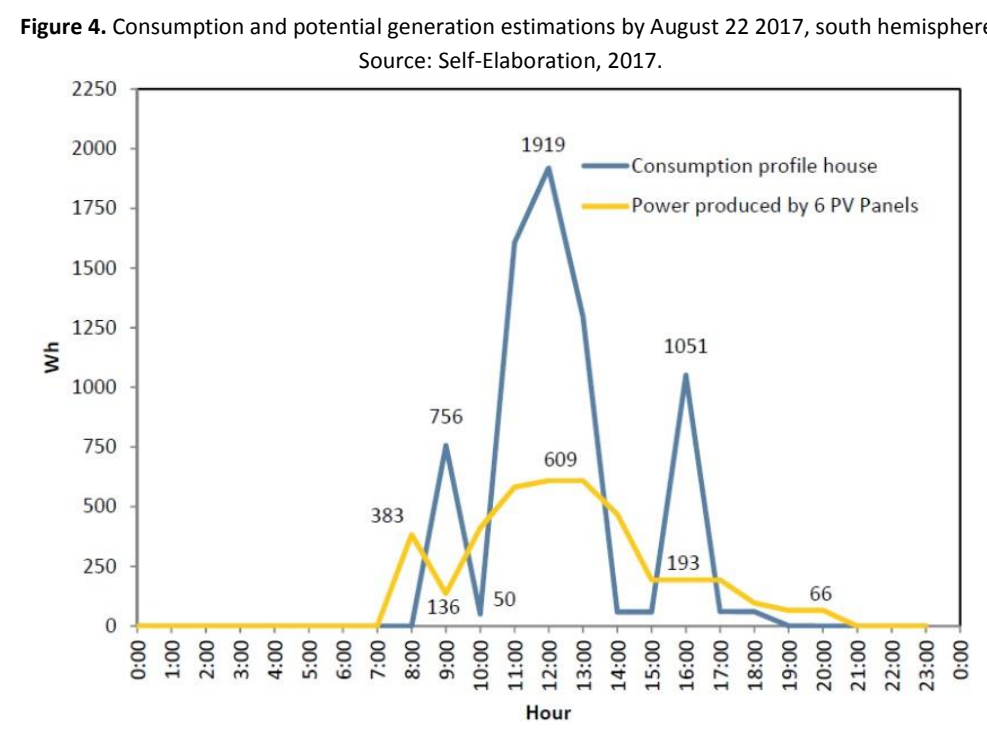

After this measurement, we will recognize time curves per hour of electricity consumption for the uses described, within the city of Santiago de Chile. The aim is to compare this curves that represent the national consumption study case for Santiago habits to international experiences, and to associate these types of consumption to the characteristics of the national electrical equipment and facilities. The measurement cycles will cover six months per selected activity and it is expected to collect a significant amount of data during 2017. The aim of the second stage is to scale the simulated database to local conditions, and therefore, to ensure the applicability of the model.

\section{Stage3: Energy Urban District identification}

The energy potential production, scaled and calibrated to the local conditions is compared to the energy demand of the different land use of the energy district under a hypothetical urban area with the purpose of establishing a balance between potential and demand.

The adjust balance between generation and consumption will enable coordination and resource allocation, as they are supported by Net-Metering, which will allow for using the grid as an energy storage system. In this way, a specific urban area or Energy Urban Districts (EUD) is obtained, with a balanced management of energy (Figure 5).

This area varies according to the time of the day and comprises mixed uses that reflect changes during the day according to the level of activity and subsequent consumption of the activities that take place within it. The EUD works as a dynamic area whose surface may change depending on the combined consumption and generation cycles of the activities carried out in the zone. This implies that an urban territory could have multiple EUDs covering different surfaces during the day.

The process of model integration consists in a common mathematical simulation of generation and consumption aimed at creating a territorial dynamic model that represents both criteria in the urban area simultaneously and thereby identify the self-sustainable energy urban units.

These analyses will be validated through fieldwork, which will be conducted at the commune of Estación Central of Santiago of Chile. The dimensioning of the self-sustainable energy units will be conducted in 2017-2018, based on data gathered by sensors and the calibration of the photovoltaic model using panels.

\section{Prototype Application: test of consistency}

To test the consistency of the model proposed, a prototype was developed using a theoretical urban area, where different types of activities were present at different volumes. In this way, the built volumes give the potential diversity 
due to the shadow cones they generate. In addition, the different activities are associated with different electricity consumption, so this consumption can be scaled in terms of the plan area of the building.

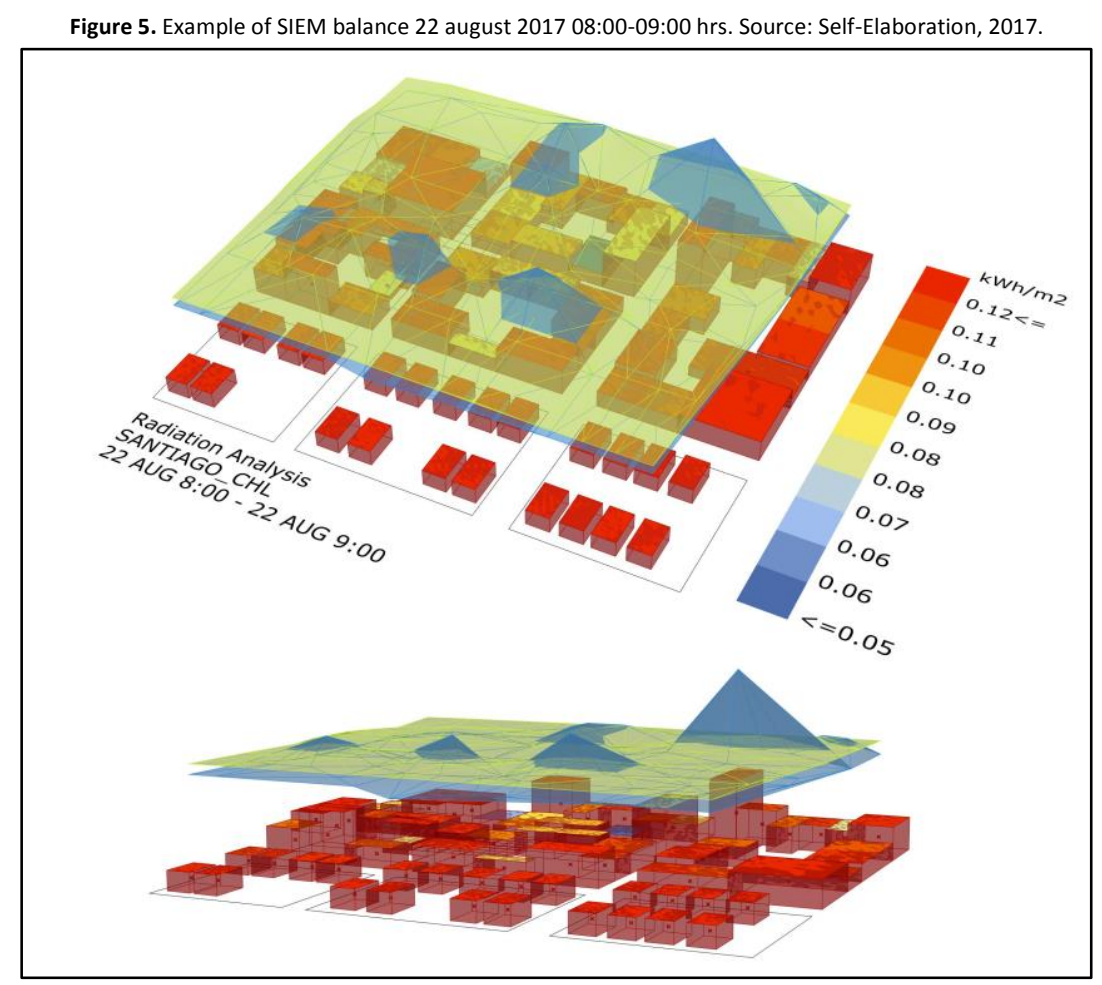

The intersection between these two planes establishes the area in which an energy balance is generated. Areas where the consumption plane (blue) is bigger than the generation plane (yellow) have an energy deficit, i.e., it is necessary an additional injection of energy to achieve balance.

In areas where the generation plane exceeds the consumption plane, there is an energy surplus, and energy can be redistributed to other areas. The contact line between these two membranes defines the variations in the energy redistribution strategy and changes dynamically during the day, as daily activities and solar radiation vary.

\section{Results}

The first analysis method is the differential average between the aggregated consumption of all units in kWh and the photovoltaic generation potential by irradiation in $\mathrm{kWh}$, at every time of the day. As a first approach, it is possible to identify different behaviors among seasons. Figure 6 compares data from January $1^{\text {st }}$ (summer), April $1^{\text {st }}$ (autumn) and July $1^{\text {st }}$ (winter).

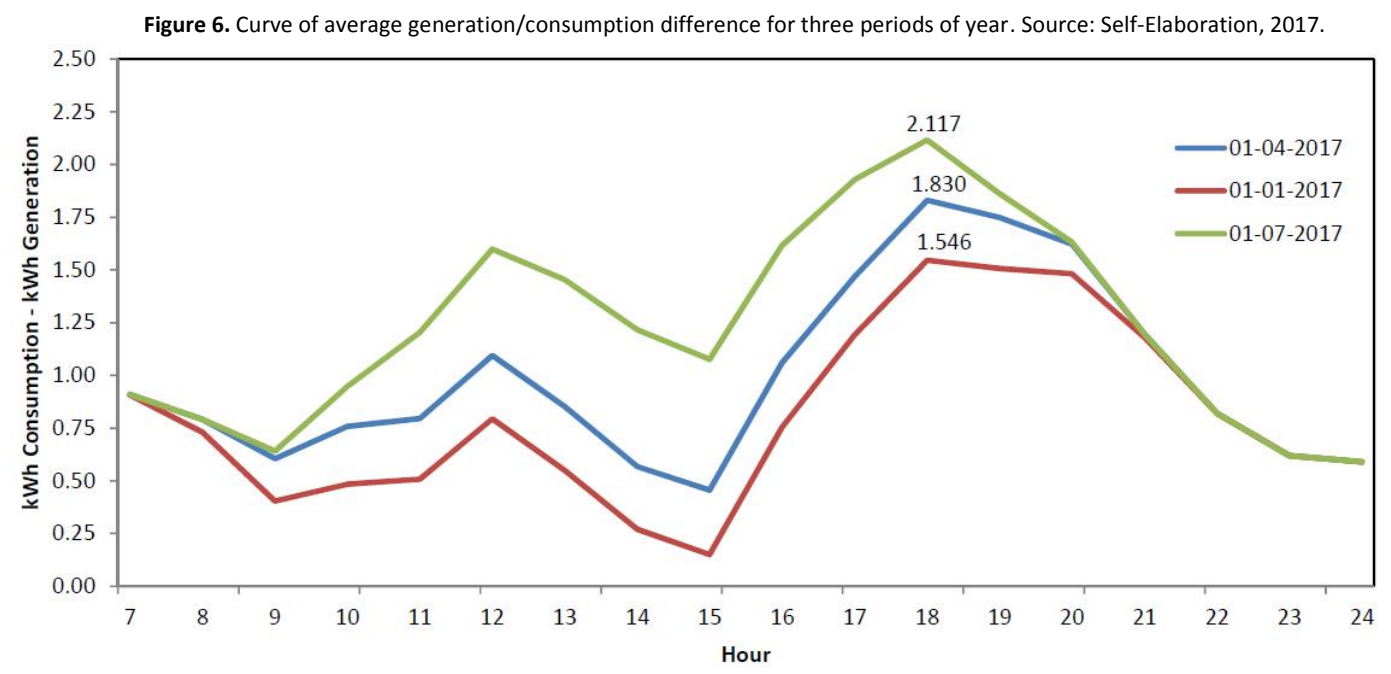


On January $1^{\text {st }}$, the maximum difference between consumption and generation averaging all the objects (buildings with different activities) under analysis reaches approximately $1.5 \mathrm{kWh}$, during afternoon time. The minimum is less than 0.2 kWh average close at noon.

The lowest value indicates the time during the day when generation-consumption compensation or balance is more feasible, as this value allows for assuming that the average difference of $0.15 \mathrm{kWh}$ is not evenly distributed and therefore some areas will have a surplus of energy that can be distributed to other areas.

On April $1^{\text {st }}$, near the equinox, it is observed that the maximum difference occurs at the same time, but at a value close to $1.8 \mathrm{kWh}$ average. The minimum value is $0.5 \mathrm{kWh}$ on average, also close to midday.

Finally, July $1^{\text {st }}$, near winter solstice, was the last date to be analyzed due to the low solar radiation of winter. In this case, the maximum difference was over $2.11 \mathrm{kWh}$ on average, and the minimum value reached $0.64 \mathrm{kWh}$ on average during the first hours in the morning. Figure 7 shows the areas where consumption of energy exceeds the potential of solar generation, in blue.

The center of each area corresponds to the starting point for energy balance optimization, for that specific time. So, from each of these centers, a number of buildings has to be selected to balance the total added consumption, and the solar energy potential, in order to define a self sustainable unit or EUD. This unit will be redefined every hour according to the evolution in time of the solar irradiation and the energy consumption curve.

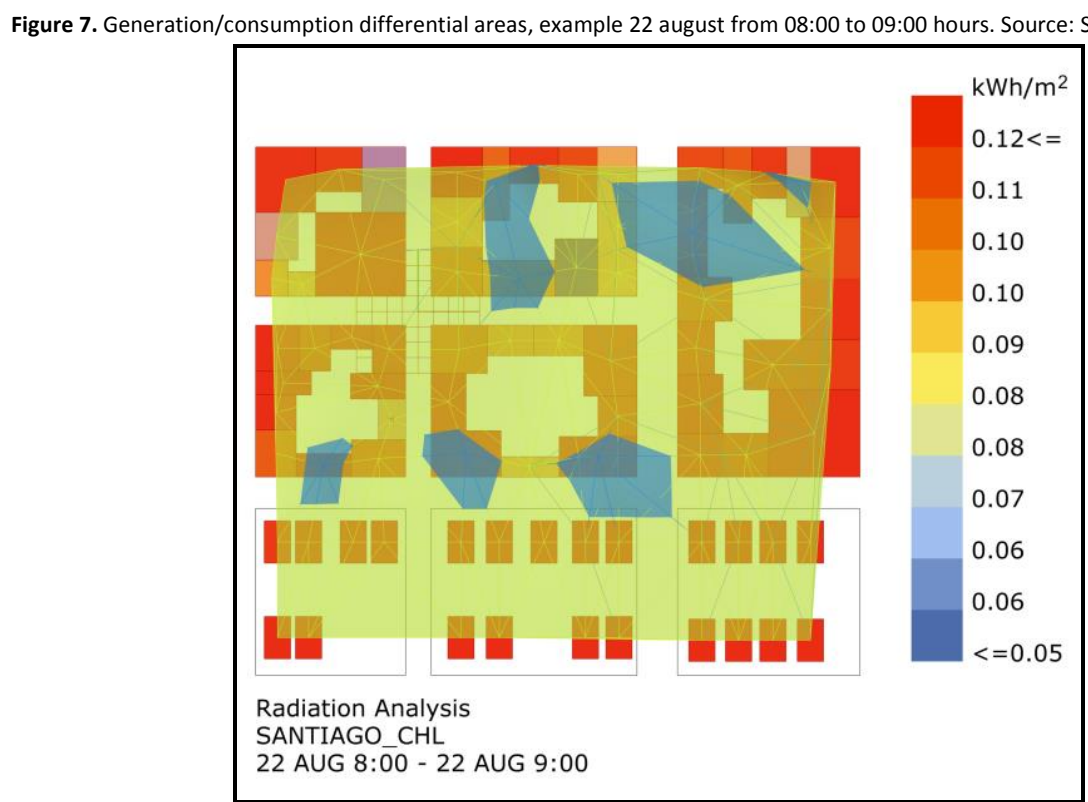

These data allows for defining the dynamic mechanism for identifying the group of buildings, now known as EUD, through which a balance between generation and consumption may be generated. The level of efficiency reached during each hour of the day will help identifying the energy distribution level necessary to maintain balance. Additionally, the level of control of energy distribution will indicate the technical requirements for the physical grid in the urban area to be managed, to achieve an efficient balance.

\section{Discussion and conclusions}

SIEM, shows efficiency in the optimization of the energy balance in a EUD after the generation and demand calibrations according to the dynamic urban grids. In that sense, the research and the proposal adds to the state of the art in the field of urban energy and the search of management models of urban energy, by means of renewable unconventional energy sources, placing the model in a specific area through the calibration of local data for Santiago of Chile.

According to the result of the test of consistency of the prototype, the potential of energy redistribution can be observed mainly in summer season (January), and in midseason (April). On the opposite, the result for the winter period (June) shows little possibility of covering the demand through redistribution of solar generated energy, unless the urban planning and norms defines typologies and urban optimized configurations that enhance solar exposure in specific EUD. 
Furthermore the potential energy redistribution between different activities or cluster profile demand on a urban grid units will depend on the specific morphologic configuration of the EUD (height, sun exposure, voids, etc.), therefore the future work applied to a real three dimensional area of the city of Santiago will allow to establish optimization correlations to improve the model.

Another critical variable is the consumption profile, according to literature (Voulis et al., 2018; Mikkola \& Lund, 2014), it is substantial to provide local data to estimate profile consumption activities, in this sense, the lack of public information available on Chile is a constraint.

Is interesting to observe that the curve consumption for the house case (Figure 4) show a different profile according to the literature (Wilke et al., 2013; Mikkola \& Lund, 2014; Voulis et al., 2018; Campos et al., 2018). That could be explained by the user behavior, where household are frequently occupied by housemaid and housewife during the noon and afternoon.

A national study (Campos et al., 2018) defines a standard annual consumption value for four type of activities; residential building ( 15 to $\left.47 \mathrm{kWh} / \mathrm{m}^{2}\right)$, hospitals building $\left(166 \mathrm{kWh} / \mathrm{m}^{2}\right)$, commercial building $\left(27 \mathrm{kWh} / \mathrm{m}^{2}\right)$ and educational building $\left(30 \mathrm{kWh} / \mathrm{m}^{2}\right)$. Despite the contribution of the study to the national scenario, the values were provided from electricity bills (month period) and case studies for the city of Concepcion, therefore the values can not be directly considered as reference on the SIEM. The stage 2 of the model aim to contribute on this knowledge gap.

Concerning the different activities in an urban area, the results of Voulis et al. (2018) shows significant difference between clusters. Concluding that residential type demand profile, use on several energy system models are only a minority of the total area ( $25 \%$ of the neighborhood and $8.6 \%$ of the municipality scale respectively) and represent a small part of the total demand energy.

According to the SIEM the study remarks the relevance to have local detailed spatial-temporal demand profiles and to use model with different activities to improve model efficiency assessment of urban energy management.

To conclude, the prototype for an urban area is feasible. In this sense, the method proposed from the real assessment of the photovoltaic generation potential and the consumption curves measured and calibrated during 2016-2017 can be used to establish an applied model for the areas under study in the municipalities of Santiago city.

Currently, data is being collected for the final adjustment of the SIEM, with the purpose of providing a validated tool to promote more efficient energy management at the urban district scale, particularly within the city of Santiago de Chile. Finally, the SIEM could be understood as an urban energy tool management, to facilitate public-private policies and actions to optimize the activities location under energy standards.

Acknowledgment

This work is part of the project financed by the Comisión Nacional de Ciencia y Tecnología (CONICYT) PAI N 791220021 , academic insertion programme 2013-2016 allocated on the Architecture School of the University of Santiago, Chile.

References

Araya-Muñoz, D., Carvajal, D., Sáez-Carreño, A., Bensaid, S., \& Soto-Márquez, E. (2014). Assessing the solar potential of roofs in Valparaíso (Chile). Energy and Buildings 69, 62-73.

Campos, P., Troncoso, L., Lund, P., Cuevas, C., Fissore, A., \& Garcia, R. (2018). Potential of distributed photovoltaics in urban Chile. Solar Energy 135, 43-49.

Chen, Y., Hong, T., \& Piette, M.A. (2017). Automatic generation and simulation of urban building energy models based on city datasets for city-scale building retrofit analysis. Apllied Energy 205, 323-335.

Corporación de Desarrollo Tecnológico CDT. (2010). Estudio de usos finales y curva de oferta de la conservación de la energía en el sector residencial (Informe final y resumen from http://energiaabierta.cl/estudios/?key=Estudio+usos+finales+y+curva+de+oferta\&categoria-e=\&organismo-e=\&from=\&to=\&lang=

Fragkias, M., Lobo, J., Strumsky, D., \& Seto, K.C (2013) Does Size Matter? Scaling of $\mathrm{CO}_{2}$ Emissions and U.S. Urban Areas. PLOS ONE 8(6): e64727. doi: 10.1371/journal.pone.0064727 
Fundación Chile (Fch). (2014). Diagnóstico energético en la comuna de Vitacura, estrategias y metas. Retrieved from https://www.vitacura.cl/resources/descargas/pdf/scam/Diagnostico\%20energetico\%20comunal\%20a\%C2\%A7o\%202014.pdf

Gomez, D.I. (2007). Análisis de estacionalidad de la curva de demanda para clientes bt-1. (Tesis de pregrado). Universidad de Chile, Santiago, Chile. Retrieved from http://www.tesis.uchile.cl/tesis/uchile/2007/gomez_da/pdf/gomez_da.pdf

Johnson, B., Starke, M., Abdelaziz, O., Jackson, R., \& Tolbert, L. (April 2014). A MATLAB based occupant driven dynamic model for predicting residential power demand. IEEE PES T\&D Conference and Exposition, Chicago, USA. doi: 10.1109/TDC.2014.6863381

Mikkola, J., \& Lund, P.D. (2014). Models for generating place and time dependent urban energy demand profiles. Applied Energy $130,256-264$.

Page, J., Robin, D., Morel, N., \& Scartezzini, J.L. (2008). A generalised stochastic model for the simulation of occupant presence. Energy and Building 40, 83-98.

Reinhart, C., \& Davila, C. (2016). Urban building energy modeling - A review of a nascent field. Building and Environment 97, $196-202$.

Voulis, N., Warnier, M., \& Brazier, F. (2018). Understanding spatio-temporal electricity demand at different urban scales: A data-driven approach. Applied Energy 230, 1157-1171.

Widen, J., \& Wackelgard, E. (2010). A high-resolution stochastic model of domestic activity patterns and electricity demand. Apllied Energy 87, 18801892.

Wilke, U., Haldi, F., Scartezzini, J-L., \& Robinson, D. (2013). A bottom-up stochastic model to predict building occupants' time-dependent activities. Building and Environment, 60, 254-264.

Yao, R., \& Steemers, K. (2005). A method of formulating energy load profile for domestic buildings in the UK. Energy and Buildings 37, 663-671.

Yeo, I., \& Lee, E. 2018. Quantitative study on environment and energy information for land use planning scenarios in eco-city planning stage. Applied Energy 230, 889-911.

Zalamea, E., \& Garcia, R. (2014). Roof characteristics for integrated solar collection in dwellings of Real-Estate developments in Concepción, Chile. Revista de la Construcción, 13 (3), 36-44.

Zhang, X., Lovati, M., Vigna, I., Widen, J., Han, M., Gal, C., \& Feng, T. (2018). A review of urban energy systems at building cluster level incorporating renewable-energy-source (RES) envelope solutions. Applied Energy 230. 1034-1056. 